(caused by anxiety, inappropriate, or paroxysmal) but even more so if it is of ventricular origin. The commonest cause of ventricular tachycardia is acute cardiac infarction, and the differentiation at the bedside between a paroxysm of ventricular tachycardia and one of supraventricular origin is by no means easy. Both usually give a heart rate of 160 or more beats a minute and one of the few differences is that in ventricular tachycardia spacing of the beats may be irregular and this may be clinically perceptible. Your expert, who recommends intravenous digoxin for heart rate that "becomes fast and irregular," could easily convert what might be a ventricular tachycardia into ventricular fibrillation.

Nor am I happy with the routine use of lignocaine to prevent primary ventricular fibrillation. This is a longstanding controversy but there is increasing opinion today not only that it may be of no use but that it may actually be harmful. Pantridge ${ }^{1}$ in 1970 found lignocaine to be ineffective against ventricular ectopic beats occurring in the first hour of the clinical onset of acute myocardial infarction. In 1971 Chopra et al showed that both ectopics of $R$ on $T$ type and multifocal ectopics were resistant to lignocaine, and that the only ectopics which were easily abolished were those occurring in diastole-and these in any case are considered relatively benign and unlikely to produce primary ventricular fibrillation. Darby et $a l^{3}$ in 1972 found that ventricular tachycardia and fibrillation occurred no less frequently in the group treated with lignocaine than in the control group. Lie et al in 1974 in 400 successive patients with acute cardiac infarction found that $5 \%$ developed primary ventricular fibrillation in the lignocainetreated group as opposed to $4.3 \%$ in the control group. Moreover, Bleifeld ${ }^{5}$ showed that ectopic beats, sinus bradycardia, and second-degree atrioventricular block were more common in the lignocaine-treated group than in the control group; and concluded that lignocaine should not be used routinely in acute cardiac infarction.

Furthermore, your expert does not mention that it is necessary whenever one gives lignocaine intravenously to give it very slowly -taking at least two minutes to administer $100 \mathrm{mg}$ of a $1 \%$ solution; otherwise toxic effects of lignocaine, such as bradycardia and hypotension, are apt to occur. This is particularly important in the elderly, where following its administration many authors ${ }^{6-8}$ have reported sinus bradycardia, ectopic beats, sinoatrial block, and even cardiac arrest.

Incidentally, I am sure that your expert is referring to dipyridamole and not disopyramide in connection with antiplatelet aggregation action.

I agree that your expert was attempting to "oversimplify" the problem, but I hope not at the expense of creating new problems.

Alan A Morgan Honorary Clinical Assistan University College Hospital,
London WC1E 6AU

\footnotetext{
${ }^{1}$ Pantridge JF. In: Scott DB, Julian DG, eds. Lidocaine in the treatment of ventricular
burgh: Livingstone, 1971:77-81.

${ }^{2}$ Chopra MP, Thadam U, Portal RW, Aber CP. Br Med f 1971 ;iii:668-70

Darby S, Cruickshank JC, Bennett MA, Pentecost BL. Lancet 1972 ; : $: 817-9$. 379-84.
}

bleifeld W, Merx W, Heinrich KW, Effert S. Eur $\mathcal{F}$ Clin Pharmacol 1973;6:119-26.

6ippestad CT, Forfang K. Br Med f 1971 ; :537. Jeresaty RM, Kahn AH, Landey AB. Chest 1972;61: 683-5.

${ }^{3}$ Cheng TO, Wadhawa J. fAMA 1973;223:790-2.

***With regard to the first point, we regret that we printed disopyramide rather than dipyridamole. The similarity between these two names presents a recurring problem. Dr Morgan points out that intravenous lignocaine must be given slowly. Of course, no drug should be given fast intravenously, and lignocaine is no exception. There are indeed papers suggesting that this drug may not be useful but at least it rarely seems to do harm. If the heart is beating very fast and the patient is hypotensive it must be slowed. Clearly an electrocardiogram, correctly interpreted, is desirable but we live in an imperfect world. We do not agree that ventricular tachycardia and rapid atrial fibrillation would often be confused. The irregularity of ventricular tachycardia is obvious on paper but usually slight compared with that of atrial fibrillation. The rate of atrial fibrillation can be slowed by a beta-blocker or by verapamil but we would not regard these as safer than digoxin in this hypothetical emergency.ED, $B M \mathcal{F}$.

Effects of naloxone on pethidine-induced neonatal depression

SIR,-We report a follow-up on children included in a neonatal study of the effects of naloxone on pethidine-induced depression of respiration, feeding, and measures of

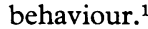

Nineteen of 29 infants included in the original trial attended for examination when aged 10-16 months. At birth nine of the infants had received placebo (normal saline) and 10 naloxone hydrochloride $200 \mu \mathrm{g}$ intramuscularly. At follow-up all were rated on the Cardiff standardisation of the Denver developmental screening test ${ }^{2}$ and were neurologically examined. No differences were found between the placebo and naloxone groups of children. Of the nine children in the placebo group one had delayed gross motor and two had delayed fine motor development. Two of the children in the naloxone group had delayed gross motor achievements.

These findings complement the results of the original trial, which indicated that $200 \mu \mathrm{g}$ intramuscular naloxone at birth seemed to reverse the undesirable effects of pethidine up to 48 hours after birth. We conclude that naloxone did not disproportionately affect development.

P C WIENER

Department of Anaesthetics,

SHEILA WALLACE University Hospital of Wales, Cardiff CF4 4XW ${ }^{1}$ Wiener PC, Hogg MPJ, Rosen M. Br Med f 1977;
ii:228-31.
${ }^{2}$ Bryant GM, Davies KJ, Newcombe RG. Develop
Med Child Neurol 1979;21:353-64.

\section{Resuscitation of the newborn}

SIR,-Dr A R J Bosley (15 December, p 1590) is incorrect in stating that the Penlon bag was not designed for use with an endotracheal tube. Mushin and Hillard mentioned such an application in their original description. ${ }^{1}$ The ability of the device to create airway pressures up to $80 \mathrm{~cm} \mathrm{H}_{2} \mathrm{O}$ was also noted. In using a leak hole in the inflating valve (instead of an ordinary blow-off valve with a preset pressure limit) the authors found that as pulmonary compliance increased (with inflation of the lungs) the maximum pressure obtainable would fall. This variable blow-off effect was justified by pointing out that the inflation pressure needed for totally airless lungs ${ }^{2}$ may often be $80 \mathrm{~cm} \mathrm{H}_{2} \mathrm{O}$, so it was illogical to use a blow-off valve preset at a lower figure. Nevertheless, in another study, which compared the Penlon bag with the Ambu neonatal bag, which uses an equally novel mechanism, again not dependent on a blow-off valve, it was found ${ }^{3}$ that both gave maximum pressures of about $85 \mathrm{~cm}$ $\mathrm{H}_{2} \mathrm{O}$ with either a high or a low resistance. However, the Penlon created a maximum pressure of $175 \mathrm{~cm} \mathrm{H} \mathrm{H}_{2} \mathrm{O}$ in a closed system compared with only $85 \mathrm{~cm} \mathrm{H}_{2} \mathrm{O}$ with the Ambu bag.

Despite these comments, these "flat" babies will not survive without someone inflating the lungs with one of a multitude of devices at his disposal. The fact that they all carry risks of pneumothorax, which may prove fatal, does not alter the situation. Endotracheal intubation of the neonate is often difficult to perform and to teach ${ }^{4}$ but may be life saving. With the appalling UK perinatal mortality statistics, can we afford to limit the resuscitation abilities of the obstetric team?

Department of Anaesthetics,

University Hospital of Leid
Leiden, The Netherlands

1 Mushin WW, Hillard EK. Br Med f 1967; : 416-7. Rosen M, Laurence KM. Lancet 1965 ;ii:721-2 Rondio Z, Rawicz M. Anaesth Resus Intensive Therap Rosen M, Mushin WW. Lancet 1968; :1307.

\section{Towards fewer handicapped children}

SIR,-Your recent leading article "Towards fewer handicapped children" (8 December, p 1458) mentions the relation between severe handicap, low birth weight $(<2500 \mathrm{~g})$, and low socioeconomic group and suggests that researchers might best employ themselves by identifying which particular components of socioeconomic deprivation result in an increased incidence of handicap. Surely part of this research has already been done.

Improved maternal nutrition during pregnancy in low socioeconomic groups is known to increase average birth weight, reduce the incidence of low-birth-weight babies $(<2500$ $\mathrm{g})$, and reduce perinatal mortality. Thus in Guatemala ${ }^{1}$ adequate maternal dietary supplementation during pregnancy in village dwellers resulted in an average fall from $30 \%$ to $9 \%$ in the incidence of low-birth-weight babies. Similar findings are demonstrated in developed countries. In Montreal ${ }^{2}$ reduction in the incidence of low-birth-weight babies $(<2500 \mathrm{~g})$ and a decrease in both perinatal and neonatal mortality was shown in a high-risk, lowsocioeconomic study group subjected to "intensive nutritional care" (counselling and dietary supplementation) throughout pregnancy.

With such improvements in birth weight and reduction in perinatal and neonatal mortality can one not expect an attendant reduction in morbidity, including mental and physical handicap? While attention is focused sharply on perinatal intensive care, could we not reduce perhaps the size of the perinatal problem by instituting "intensive nutritional care," including dietary supplementation 